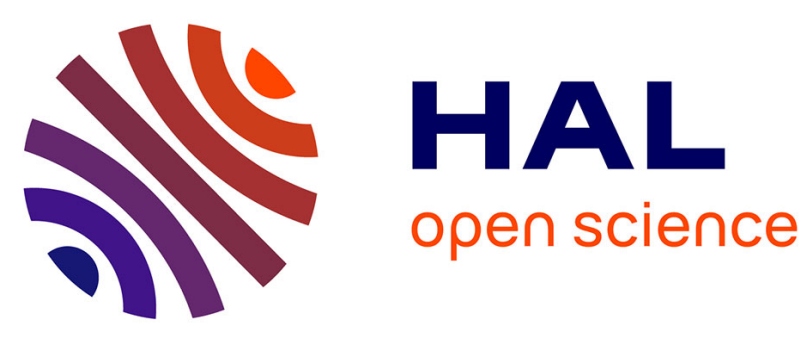

\title{
Alloying effects on the critical layer thickness in InxGa1-xAs/InP heterostructures analyzed by Raman scattering
}

P.S. Pizani, T.M. Boschi, F. Lanciotti, Jr, J. Groenen, Robert Carles, P. Maigné, M. Gendry

\section{To cite this version:}

P.S. Pizani, T.M. Boschi, F. Lanciotti, Jr, J. Groenen, Robert Carles, et al.. Alloying effects on the critical layer thickness in InxGa1-xAs/InP heterostructures analyzed by Raman scattering. Applied Physics Letters, 1998, 72 (4), pp.436-438. 10.1063/1.120800 . hal-02111887

\section{HAL Id: hal-02111887 \\ https://hal.science/hal-02111887}

Submitted on 26 Apr 2019

HAL is a multi-disciplinary open access archive for the deposit and dissemination of scientific research documents, whether they are published or not. The documents may come from teaching and research institutions in France or abroad, or from public or private research centers.
L'archive ouverte pluridisciplinaire HAL, est destinée au dépôt et à la diffusion de documents scientifiques de niveau recherche, publiés ou non, émanant des établissements d'enseignement et de recherche français ou étrangers, des laboratoires publics ou privés. 


\section{Alloying effects on the critical layer thickness in $\operatorname{In}_{x} \mathrm{Ga}_{1-x} \mathrm{As} / \mathrm{InP}$ heterostructures analyzed by Raman scattering}

Cite as: Appl. Phys. Lett. 72, 436 (1998); https://doi.org/10.1063/1.120800

Submitted: 21 April 1997 . Accepted: 21 November 1997. Published Online: 04 June 1998

P. S. Pizani, T. M. Boschi, F. Lanciotti, J. Groenen, R. Carles, P. Maigné, and M. Gendry

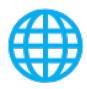

\section{ARTICLES YOU MAY BE INTERESTED IN}

Raman scattering in InAs ${ }_{-x} \mathrm{Sb}_{x}$ grown by organometallic vapor phase epitaxy

Applied Physics Letters 53, 886 (1988); https://doi.org/10.1063/1.100104

Long-range order in InAsSb

Applied Physics Letters 54, 1154 (1989); https://doi.org/10.1063/1.100746

Tensile and compressive strain relief in $\operatorname{In}_{X} \mathrm{Ga}_{1-X}$ As epilayers grown on InP probed by Raman scattering

Journal of Applied Physics 82, 803 (1997); https://doi.org/10.1063/1.365775

\section{Applied Physics Reviews}

Now accepting original research 


\title{
Alloying effects on the critical layer thickness in $\ln _{x} \mathrm{Ga}_{1-x} \mathrm{As} / \mathrm{InP}$ heterostructures analyzed by Raman scattering
}

\author{
P. S. Pizani, ${ }^{\text {a) }}$ T. M. Boschi, and F. Lanciotti, Jr. \\ Departamento de Física, Universidade Federal de São Carlos, 13565-905 São Carlos, SP, Brazil \\ J. Groenen and R. Carles \\ Laboratoire de Physique des Solides, Université Paul Sabatier, 31062 Toulouse Cedex, France \\ P. Maignéb) \\ Communications Research Centre, Ottawa, Ontario, Canada \\ M. Gendry \\ Laboratoire d'Electronique, URA CNRS 848, Ecole Centrale de Lyon, 69131 Ecully Cedex, France
}

(Received 21 April 1997; accepted for publication 21 November 1997)

\begin{abstract}
Raman scattering has been used to estimate the critical layer thickness and to analyze the alloying effect on strain relaxation in $\mathrm{In}_{x} \mathrm{Ga}_{1-x}$ As layers grown by molecular beam epitaxy on InP [001]-oriented substrate, for $x$ ranging from 0.0 to 1.0. Measurements of longitudinal optical GaAs-like phonon frequency and Raman linewidth showed that the indium/gallium ratio contents greatly influences the strain relaxation. A comparison between Raman and x-ray diffraction measurements of relaxation ratios as a function of layer thickness is presented. The results can be explained in terms of the combined effect of strain and chemical and structural disorder. (C) 1998 American Institute of Physics. [S0003-6951(98)00404-5]
\end{abstract}

A fundamental problem in semiconductor heteroepitaxy is controlling the crystalline quality of the layer, since it determines the optoelectronic properties of the materials. In a heterostructure, strains may arise due to a lattice mismatch between the layer and its substrate and/or to the differences in their thermal expansion coefficients. Some applications take advantage of the new properties of these strained structures, since their properties can be modulated as required for specific devices. ${ }^{1}$ However, strain relaxation by creation of structural defects leads to a degradation of the properties of the materials and therefore of device performance. For a given heterostructure, the threshold of the relaxation process depends on the growth conditions (temperature, growth rate, and substrate orientation). ${ }^{2,3}$ The relaxation process starts when the elastic energy accumulated in the layer exceeds the energy necessary for defect creation. As the accumulated elastic energy depends on layer thickness, it takes place when a layer exceeds a certain critical thickness (CLT). ${ }^{4}$ The most used techniques to experimentally determine CLT are photoluminescence (PL), ${ }^{5}$ reflection high energy electron diffraction (RHEED), ${ }^{6}$ and x-ray diffraction (XRD). ${ }^{7}$

Previously reported experimental studies on strain relaxation and critical layer thickness are devoted mainly to the $\mathrm{In}_{x} \mathrm{Ga}_{1-x}$ As grown on GaAs substrate, ${ }^{8}$ where the strains are always compressives. For $\operatorname{In}_{x} \mathrm{Ga}_{1-x}$ As grown on InP, no extensive Raman studies exist, ${ }^{9}, 10$ although this heterostructure is very interesting because the epilayer is submitted to compressive $(x>0.53)$ or tensile $(x<0.53)$ strains, in addition to chemical and structural disorder. These characteristics of the heterostructure greatly influence the vibrational spectra of the layer material, making the Raman scattering a powerful technique for their study. Strains lead to changes in phonon

\footnotetext{
${ }^{\text {a)} E l e c t r o n i c ~ m a i l: ~ d p s p @ p o w e r . u f s c a r . b r ~}$

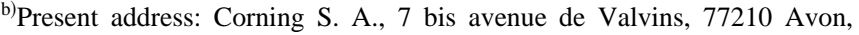
France.
}

frequencies and disorder effects to the breakdown of Raman selection rules and broadening of the Raman peaks. Moreover, contrary to the other optical techniques such as photoluminescence, measurements may be performed at room temperature. In the present letter we report an original Raman scattering study on $\operatorname{In}_{x} \mathrm{Ga}_{1-x}$ As epilayers for $x=0.00$, $0.25,0.42,0.53,0.75,0.82,0.85$, and 1.00 . Analysis of the Raman spectra allowed us to characterize the strain relaxation and to estimate the critical layer thickness.

The samples were grown in a Riber 2300 molecular beam epitaxy (MBE) system equipped with RHEED. A lattice-matched $\mathrm{In}_{0.53} \mathrm{Ga}_{0.47}$ As layer was grown on the InP[001] oriented substrate before epitaxy of the latticemismatched $\operatorname{In}_{x} \mathrm{Ga}_{1-x}$ As layers. For each indium concentration, two layers of different thicknesses were grown. Details of growth conditions, TEM, and RHEED results have already been reported. ${ }^{11,12}$

The Raman measurements were performed with a T800 Coderg triple monochromator coupled with a cooled GaAs photomultiplier and a conventional photon counting system. The $488 \mathrm{~nm}$ line of an argon ion laser was used as exciting light. The output power of the laser beam was kept within $200 \mathrm{~mW}$ and cylindrical lenses were used to avoid overheating of the sample. Experimental geometry was always in backscattering and the measurements performed at room temperature.

Figure 1 shows the frequency of the longitudinal optical (LO) GaAs-like phonon mode as a function of the thickness of the $\operatorname{In}_{x} \mathrm{Ga}_{1-x}$ As layer for several indium concentrations. The values on the ordinate axis were calculated for strained layers pseudomorphically grown on InP (Ref. 13) and the values to the right are the frequencies for the solid solution. ${ }^{14}$ This figure clearly shows a smooth evolution of the strain relaxation. These data enable us to estimate the CLT as a function of indium concentration. The value of $t_{c}$ was taken 


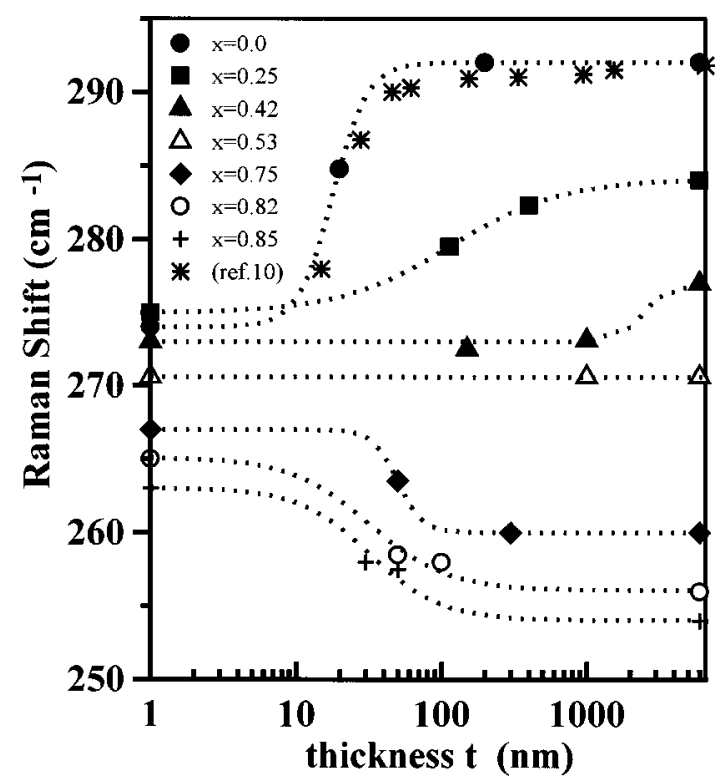

FIG. 1. Frequencies of the LO GaAs-like phonon as a function of thickness layers for several In concentrations. The values on the ordinates axis are the calculated frequencies of the LO phonons from layers matched to the substrate (pseudomorphic); the values at the right are the frequencies from the solid solution (completely relaxed) from Ref. 14. Stars are data from Ref. 10. The dotted lines are fittings.

at the inflection point of the fitted Boltzmann function (dotted lines in Fig. 1); To fit, we have imposed $d \omega / d t=0$ at $t$ $=0$ and $t=\infty$, where $t$ is the thickness.

Figure 2 shows the plot of the estimated values of the critical layer thickness obtained from the data above. This figure also shows the theoretical calculations for the critical layer thickness from the Mathews-Blackslee (MB) model. ${ }^{15}$ It is interesting to note that for the region of tensile strains and low indium concentration $(x<0.53)$ the values are greater than theoretically predicted, while for the region of compressive strains and large indium concentration ( $x$ $>0.53$ ) the values are in good agreement with the MB model.

Figure 3 shows the full width at half maximum (FWHM)

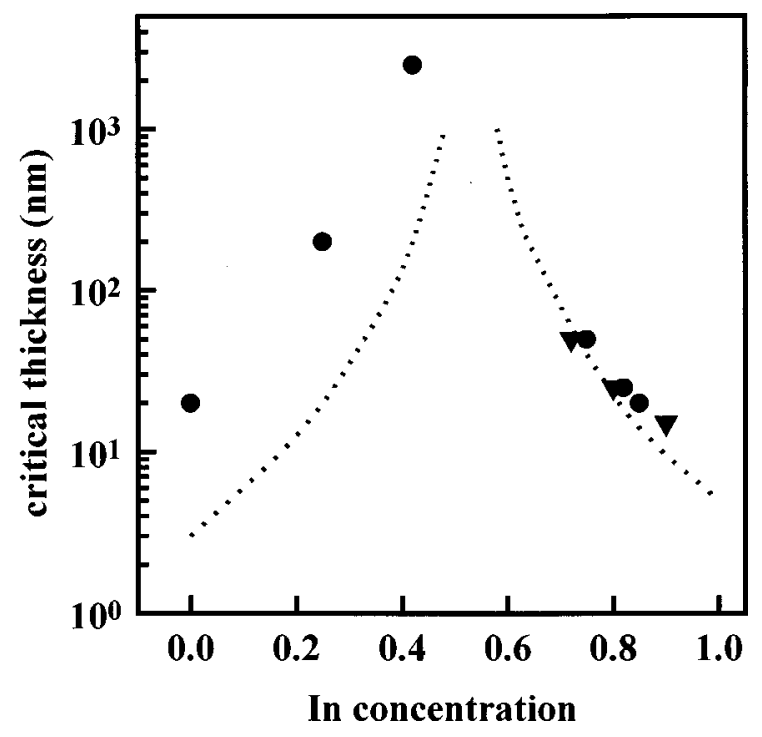

FIG. 2. Critical layer thickness estimated from Raman data (full circles), calculated from MB model (dotted lines) and from Ref. 6 (triangles).

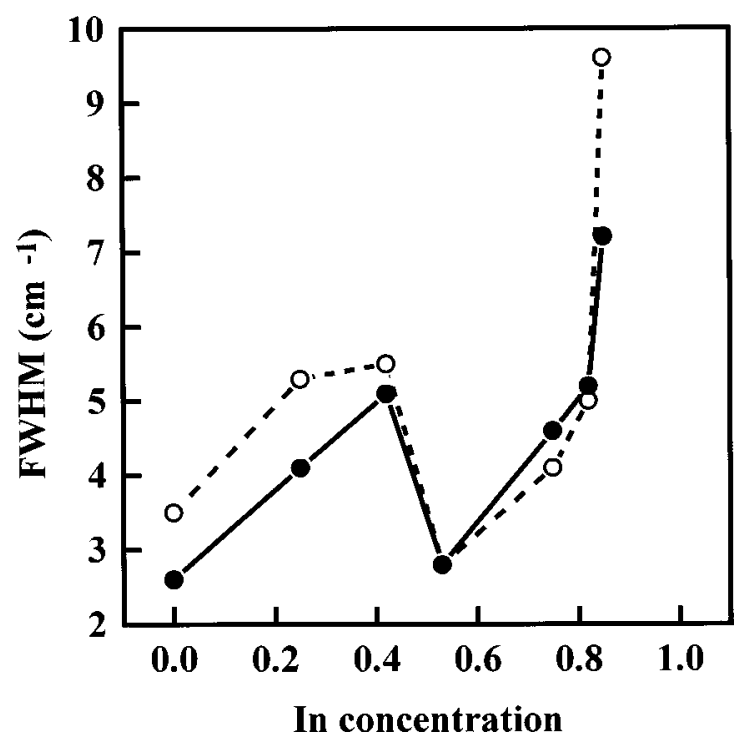

FIG. 3. Deconvoluted full width at half maximum (FWHM) of the LO GaAs-like phonons from Raman measurements: The full circle indicates the values from thicker layers and open circles from thinner layers. The dotted and full lines are a guide for the eye (see Ref. 17).

of the LO GaAs-like phonon Raman peak as a function of indium concentration, for two different layer thicknesses. First, there are maximum broadenings at about $x \sim 0.3$ and 0.85 , with a minimum at $x=0.53$. These results are in good agreement with double crystal x-ray diffraction (DXRD) measurements from Ref. 16. Second, the broadening is greater for thinner layers than for thicker ones in the region of low indium contents, a result suggesting that the structural disorder is more important at the interface between the layer and substrate. Third, for the region between 0.53 and 0.82 , the broadenings are approximately the same for both thicknesses, suggesting a two-dimensional (2D) growth mode, with a 2D/3D transition for $x \sim 0.85$ (see a more detailed discussion in Ref. 17).

Table I shows some characteristics of the samples and the most accurate values of $\mathrm{x}$-ray diffraction relaxation ratio $R \%$ (as defined in Ref. 12) determined from XRD data and the Raman relaxation ratio $\omega \%$ determined from the data in Fig. 1. We have defined $\omega \%=\left(\omega_{m}-\omega_{0} / \omega_{\mathrm{ss}}-\omega_{0}\right) \times 100 \%$, where $\omega_{m}, \omega_{0}$, and $\omega_{\mathrm{ss}}$ are the measured, completely matched, and completely relaxed (strain free solid solution) LO GaAs-like phonon frequencies, respectively. From the data, the values of $\omega \%$ and $R \%$ are both noticeably greater for compressive strains than tensile ones, indicating an asymmetry in strain relaxation. The differences between $R \%$ and $\omega \%$ for each sample could well be attributed to intrinsic differences between techniques: while Raman scattering probes phonons in small regions (the penetration depth of the light for the $488 \mathrm{~nm}$ line is about $50-15 \mathrm{~nm}$, for GaAs and InAs, respectively), XRD probes the bulk layer, providing averaged structural information.

The above results cannot be explained in terms of strain effects or chemical and structural disorder separately, since the maxima of the strains are localized at $x=0.0$ (tensile) and at $x=1.0$ (compressive), where there is a minimum of chemical disorder. On the other hand, the maximum of chemical disorder is localized at $x=0.50$, where there is a 
TABLE I. Some characteristics of the $\operatorname{In}_{x} \mathrm{Ga}_{1-x}$ As epilayers: $x$ is the In content, $t$ is the layer thickness, $\omega \%$ is the relaxation ratio from Raman measurements as defined in the text, and $R \%$ is the relaxation ratio from XRD measurements.

\begin{tabular}{crrr}
\hline \hline$x$ & $t(\mathrm{~nm})$ & $\omega \%$ & $R \%$ \\
\hline 0.0 & 20 & 55 & --- \\
& 200 & 100 & 93 \\
0.25 & 114 & 40 & --- \\
& 400 & 80 & 100 \\
0.42 & 150 & 0 & 26 \\
& 1000 & 15 & 60 \\
0.53 & 1000 & 100 & 100 \\
0.65 & 50 & 30 & 10 \\
& 520 & 100 & 70 \\
0.75 & 50 & 60 & 30 \\
& 300 & 100 & 85 \\
0.82 & 50 & 70 & --- \\
& 100 & 85 & 60 \\
0.85 & 29 & 55 & --- \\
& 50 & 70 & --- \\
1.0 & 20 & --- & 95 \\
\hline \hline
\end{tabular}

minimum of strain. Only the combination of these effects can explain the results.

The larger FWHM for regions with greater indium concentrations is consistent with smaller values for critical layer thickness obtained from our Raman data: the critical layer thickness decreases while structural disorder increases. Measurements of Raman selection rules (not shown here) corroborated the fact that the disorder effects are more important for $x>0.53$, shown by the activation of the TO InAs-like phonon mode, normally forbidden in backscattering geometry.

In conclusion, we have shown that Raman spectroscopy is a powerful technique for probing strain relaxation in heterostructures: it is an easy alternative way to directly determine critical layer thickness. In the system (In, Ga)As/InP, the critical layer thickness is greater than the theoretical predictions for low indium concentrations and tensile strains, while it agrees with the MB model for large indium concentrations and compressive strains. Moreover, the Raman and
$\mathrm{XRD}$ relaxation ratios showed asymmetry in strain relaxation in compressive strained layers compared to the tensile case. The results lead to the conclusion that the strain due to the lattice mismatch is not the only factor determining the crystalline quality of the layer and the critical layer thickness: the indium/gallium ratio contents have an important role in this system.

One of the authors (P.S.P.) would like to thank the Brazilian agencies CNPq-RHAE, CAPES, and FAPESP for financial support.

${ }^{1}$ L. R. Tessler, C. Hermann, G. Lampel, Y. Lassailly, C. Fontaine, E. Daran, and A. Munõz-Yague, Appl. Phys. Lett. 64, 859 (1994).

${ }^{2}$ S. Z. Chang, T. C. Chang, and S. C. Lee, J. Appl. Phys. 73, 4916 (1993).

${ }^{3}$ M. Gendry and G. Hollinger, in Proceedings of the First International Conference on Semiconductor Heteroepitaxy Montpellier, 1995, edited by B. Gil and R. L. Aulombard (World Scientific, Singapore, 1995).

${ }^{4}$ J. Singh, Physics of Semiconductors and Their Heterostructures (McGraw-Hill, New York, 1993), p. 218.

${ }^{5}$ M. J. Ekenstedt, T. G. Anderson, and S. M. Wang, Phys. Rev. B 48, 5289 (1993); D. Morris, A. P. Roth, R. A. Masut, C. Lacelle, and J. L. Brebner, J. Appl. Phys. 64, 4135 (1988).

${ }^{6}$ M. Tacano, Y. Sugiyama, and Y. Takeichi, Appl. Phys. Lett. 58, 2429 (1991); P. R. Berger, K. Chang, P. Bhattacharya, J. Singh, and K. K. Bajaj, ibid. 53, 684 (1988).

${ }^{7}$ Y. C. Chen, P. K. Bhattacharya, and J. Singh, J. Vac. Sci. Technol. B 10, 769 (1992); C. R. Wie, J. Appl. Phys. 65, 2267 (1989).

${ }^{8}$ G. Burns, C. R. Wie, F. H. Dacol, G. D. Pettit, and J. M. Woodall, Appl. Phys. Lett. 51, 1919 (1987).

${ }^{9}$ E. Carlino, C. Giannini, L. Tapfer, M. Catalano, E. Tournié, Y. H. Zhang, and K. H. Ploog, J. Appl. Phys. 78, 2403 (1995).

${ }^{10}$ G. Attolini, L. Francesio, P. Franzosi, C. Pelosi, S. Gennari, and P. P. Lottici, J. Appl. Phys. 75, 4156 (1994).

${ }^{11}$ M. Gendry, V. Drouot, C. Santinelli, G. Hollinger, C. Miossi, and M. Pitaval, J. Vac. Sci. Technol. B 10, 1829 (1992).

${ }^{12}$ P. Maigné, M. Gendry, T. Venet, Y. Tahri, and G. Hollinger, Appl. Phys. Lett. 69, 682 (1996)

${ }^{13}$ E. Anastassakis, J. Appl. Phys. 68, 4561 (1990).

${ }^{14}$ G. Landa, R. Carles, and J. B. Renucci, Solid State Commun. 86, 351 (1993).

${ }^{15}$ J. W. Matthews and A. E. Blakeslee, J. Cryst. Growth 27, 118 (1974).

${ }^{16}$ S. Z. Chang, S. C. Lee, C. R. Chen, and L. J. Chen, J. Appl. Phys. 75, 1511 (1994).

${ }^{17}$ J. Groenen, G. Landa, R. Carles, P. S. Pizani, and M. Gendry, J. Appl. Phys. 82, 803 (1997). 